\title{
Air and water flows in a vertical sand column
}

\author{
Xingxing Kuang, ${ }^{1}$ Jiu Jimmy Jiao, ${ }^{1}$ Li Wan, ${ }^{2}$ Xusheng Wang, ${ }^{2}$ and Deqiang $\mathrm{Mao}^{2,3}$ \\ Received 22 December 2009; revised 4 January 2011; accepted 23 February 2011; published 14 April 2011. \\ [1] The unsteady state drainage of water from a vertical sand column with and without a \\ finer layer on the top was studied theoretically and experimentally to investigate the airflow \\ generated by the finer layer. The sand column, saturated at its lower portion and initially \\ in the condition of hydrostatic equilibrium, is drained at its bottom at constant head. The \\ results show that significant vacuum can be generated in the vadose zone of the column with \\ a finer layer on the top. The vacuum increases quickly in the earlier stage of the drainage, \\ reaches a maximum, and gradually becomes zero. Because of the effect of the vacuum in \\ the vadose zone, water is held in and the cumulative outflow from the column with \\ the finer layer is much smaller than without the layer during most of the drainage process. \\ Ordinary differential equations (ODE), which require only saturated hydraulic properties \\ of the porous media, are derived to predict the location of the surface of saturation and \\ vacuum in the vadose zone in air-water two-phase flow. The solutions of ODE match very \\ satisfactorily with the experimental data and give better results than TOUGH2.
}

Citation: Kuang, X., J. J. Jiao, L. Wan, X. Wang, and D. Mao (2011), Air and water flows in a vertical sand column, Water Resour. Res., 47, W04506, doi:10.1029/2009WR009030.

\section{Introduction}

[2] The drainage of fluids from homogeneous porous media has been studied for a long time. Studies may be classified into two groups: the saturated flow approach and the saturated-unsaturated flow approach.

[3] The first group focuses on water flow below the water table only. Youngs [1960] derived an approximate equation describing the cumulative outflow based on the capillary tube analogy and a constant drainable porosity. Arbhabhirama and Ahmed [1973] considered the effect of pore size distribution in the capillary tube model and derived approximate solutions for nonsteady column drainage. On the basis of a concept of instantaneous and complete drainage at the water table, Ligon et al. [1962] derived equations to predict the drawdown of the surface of saturation in the column and the rate of outflow. Kroszynski [1975] presented a more detailed list of such kind of work.

[4] The second group regards the water both above and below the water table as a continuum and uses the Richards' equation [Richards, 1931] to describe the flow process. Fujioka and Kitamura [1964] assumed a constant moisture diffusivity to linearize the Richards' equation and derived an approximate solution for hydraulic head distribution in the column. Kroszynski [1975] derived an approximate analytical solution for predicting the pressure head and the drawdown of the surface of saturation. Many researchers [e.g., Philip, 1960; Sander et al., 1988; Ross and Parlange,

\footnotetext{
${ }^{1}$ Department of Earth Sciences, University of Hong Kong, Hong Kong, China.

${ }^{2}$ School of Water Resources and Environment, China University of Geosciences, Beijing, China.

${ }^{3}$ Department of Hydrology and Water Resources, University of Arizona, Tucson, Arizona, USA.
}

Copyright 2011 by the American Geophysical Union 0043-1397/11/2009WR009030
1994; Parlange et al., 1997; Hogarth and Parlange, 2000; Menziani et al., 2007] derived analytical solutions to the Richards' equation to investigate water flow in an unsaturated zone. Triadis and Broadbridge [2010] systematically summarized analytical solutions of the Richards' equation.

[5] Numerical solutions for the drainage of vertical soil columns were given by a number of researchers, such as Watson [1967], Hornberger and Remson [1970], and Kroszynski [1975]. A lot of numerical algorithms have been derived to solve the Richards' equation for saturated-unsaturated flow [e.g., Celia et al., 1990; Kirkland et al., 1992; Clement et al., 1994; Rathfelder and Abriola, 1994; Babajimopoulos, 2000; Kavetski et al., 2002; Casulli and Zanolli, 2010]. A detailed list of these mathematical models was given by Clement et al. [1994]. A full list of numerical methods to solve the Richards' equation is given by Kosugi [2008], Casulli and Zanolli [2010], and Juncu et al. [2010].

[6] The drainage of fluids from porous media is traditionally described by the single-phase water flow approach, and the air phase is ignored. However, there are some situations where the role of the air phase cannot be neglected. Bouwer and Rice [1978] concluded that delayed release of pore water from a pumped, unconfined aquifer can be caused by restricted air movement in the vadose zone due to layers of high water content. Vachaud et al. [1973] observed that the pressure in the stratified unsaturated zone is significantly different from the external atmospheric pressure and concluded that the impact of air must be taken into account in determining the soil water suction. They suggested that the flow equations must be written in terms of two-phase immiscible fluid flow. Under these circumstances, the singlephase water flow theory is inadequate and the two-phase immiscible fluid flow approach must be used to interpret the drainage process. Jiao and Guo [2009] conducted a theoretical study of pumping-induced airflow in an unconfined aquifer capped with a low-permeability layer and concluded that if airflow caused by the low-permeability cap was 
ignored, the errors in estimated drawdown and then aquifer parameters could be significant.

[7] Multiphase flow in porous media has been studied for more than 60 years. There has been a lot of work on twophase flow in porous media since the 1970s in both soil water hydrology and oil reservoir engineering. A full list of such work is impossible herein. Morel-Seytoux [1973] presented an excellent development of the various forms of the multiphase flow governing equations. Parker [1989] and Muccino et al. [1998] presented comprehensive reviews on multiphase flow in porous media. The various two-phase flow models were reviewed by Vauclin [1989]. Solutions for simultaneous flow of air and water in the vadose zone are mainly on infiltration into the vadose zone with air effects [e.g., Touma et al., 1984; Morel-Seytoux and Billica, 1985; Touma and Vauclin, 1986; Weir and Kissling, 1992; Wang et al., 1997; Cueto-Felgueroso and Juanes, 2008]. Weeks [2002] and Guo et al. [2008] investigated the effects of airflow induced by rain infiltration on water level changes in a well in an unconfined aquifer. Jiao and Li [2004] and Guo and Jiao [2008] developed numerical solutions for air-water twophase flow caused by periodic water level fluctuations. Li and Jiao [2005] derived an analytical solution for airflow in the unsaturated zone induced by fluctuating water table.

[8] The numerical simulation of multiphase flow has attracted more attention than experimental work [Kueper and Frind, 1991]. A number of numerical simulators have been developed to simulate multiphase flow [e.g., Faust, 1985; Kuppusamy et al., 1987; Faust et al., 1989; Kueper and Frind, 1991; Celia and Binning, 1992; Class et al., 2002; Amaziane et al., 2010]. Well-documented software is also available, such as TOUGH2 [Pruess et al., 1999] and NAPL [Guarnaccia et al., 1997]. Miller et al. [1998] reviewed the modeling of multiphase flow and transport in heterogeneous porous media. Niessner and Hassanizadeh [2008] developed a new numerical model for two-phase flow in porous media including fluid-fluid interfacial area. Hoteit and Firoozabadi [2008] considered capillary heterogeneity in numerical modeling of two-phase flow in heterogeneous porous media. On the basis of the immiscible two-phase flow of water and oil in saturated heterogeneous soil columns, Aggelopoulos and Tsakiroglou [2009] developed a multiple flow path model for immiscible displacement in heterogeneous soil columns.

[9] The governing equations of two-phase flow are strongly nonlinear, so analytical solutions incorporating fully the effects of gravity and capillarity in transient multiphase flow through heterogeneous porous media are not tractable [Kueper and Frind, 1991]. Buckley and Leverett [1942] first derived a classical solution for one-dimensional, horizontal two-phase flow without capillary forces. McWhorter and Sunada [1990] derived solutions for the horizontal, transient flow of two viscous, incompressible fluids, in which the effect of capillarity was fully incorporated. Fokas and Yortsos [1982] derived an exact solution for one-dimensional twophase flow in a semi-infinite, horizontal reservoir for a constant flux boundary condition. Rogers et al. [1983] extended the solution of Fokas and Yortsos [1982] to take gravitational effects into consideration. Sander et al. [1993] derived an exact solution to the one-dimensional diffusion-convection equation for two-phase flow in porous media with Dirichlet boundary conditions. Sander et al. [2005] derived exact solutions to radially symmetric two-phase flow into an infi- nite medium under a constant flux boundary condition. More recently, on the basis of the work of McWhorter and Sunada [1990], Fučik et al. [2007] derived a semianalytical solution for one-dimensional two-phase flow through a homogeneous porous medium.

[10] The objective of this study is to investigate experimentally and theoretically the effects of air phase on water flow during the drainage of a vertical sand column. Cumulative outflow and vacuum in the vadose zone of the column were measured. An attempt is made to derive solutions for one-dimensional, vertical air-water two-phase flow problem and use the solutions to interpret the experimental data.

\section{Mathematical Model}

\subsection{Saturated-Unsaturated Flow}

[11] The physical system first consists of a vertical cylindrical sand column without the finer layer on the top (Figure 1). Flow within this column takes place in the vertical direction only. The initial position of the water table is within the coarse sand layer, and thus a vadose zone exists. The column is allowed to drain at its bottom at constant head.

[12] The governing equation and auxiliary conditions are

$$
\begin{gathered}
\frac{\partial \theta}{\partial t}=\frac{\partial}{\partial z}\left(K \frac{\partial \psi}{\partial z}\right)+\frac{\partial K}{\partial z} \\
\psi(z, 0)=s_{0}-z, 0 \leq z \leq L_{2} \\
\psi(0, t)=h_{0}, t>0 \\
\frac{\partial \psi}{\partial z}\left(L_{2}, t\right)=-1, t>0
\end{gathered}
$$

where $\theta$ is volumetric water content, $K$ is hydraulic conductivity, $\psi$ is the pressure head or capillary pressure head, $z$ is the vertical coordinate given height above the bottom of the column as datum, $t$ is time, $s_{0}$ is the initial position of the water table, $L_{2}$ is the total length of the sand column, and $h_{0}$ is the constant hydraulic head at the bottom of the column.

[13] Equation (1a) is the governing equation for onedimensional vertical saturated-unsaturated flow [e.g., Hillel, 1980; Allen and Murphy, 1986; Celia et al., 1987]. The mixed form of Richards' equation is used for mass conservation [Celia et al., 1990]. Equation (1b) is the initial condition which gives the initial distribution of pressure head in the column. Equation (1c) represents the constanthead boundary condition at the bottom of the column. Equation (1d) is the no-flow boundary condition at the column top.

\subsection{Air-Water Two-Phase Flow Approximate Solutions}

\subsubsection{Water Flow}

[14] A finer layer is then placed on the top of the sand column (Figure 1). The rate of discharge of water per unit cross-sectional area at any given time is given by Darcy's law:

$$
q_{w}=K_{s} \frac{h-h_{a}-h_{0}}{h},
$$




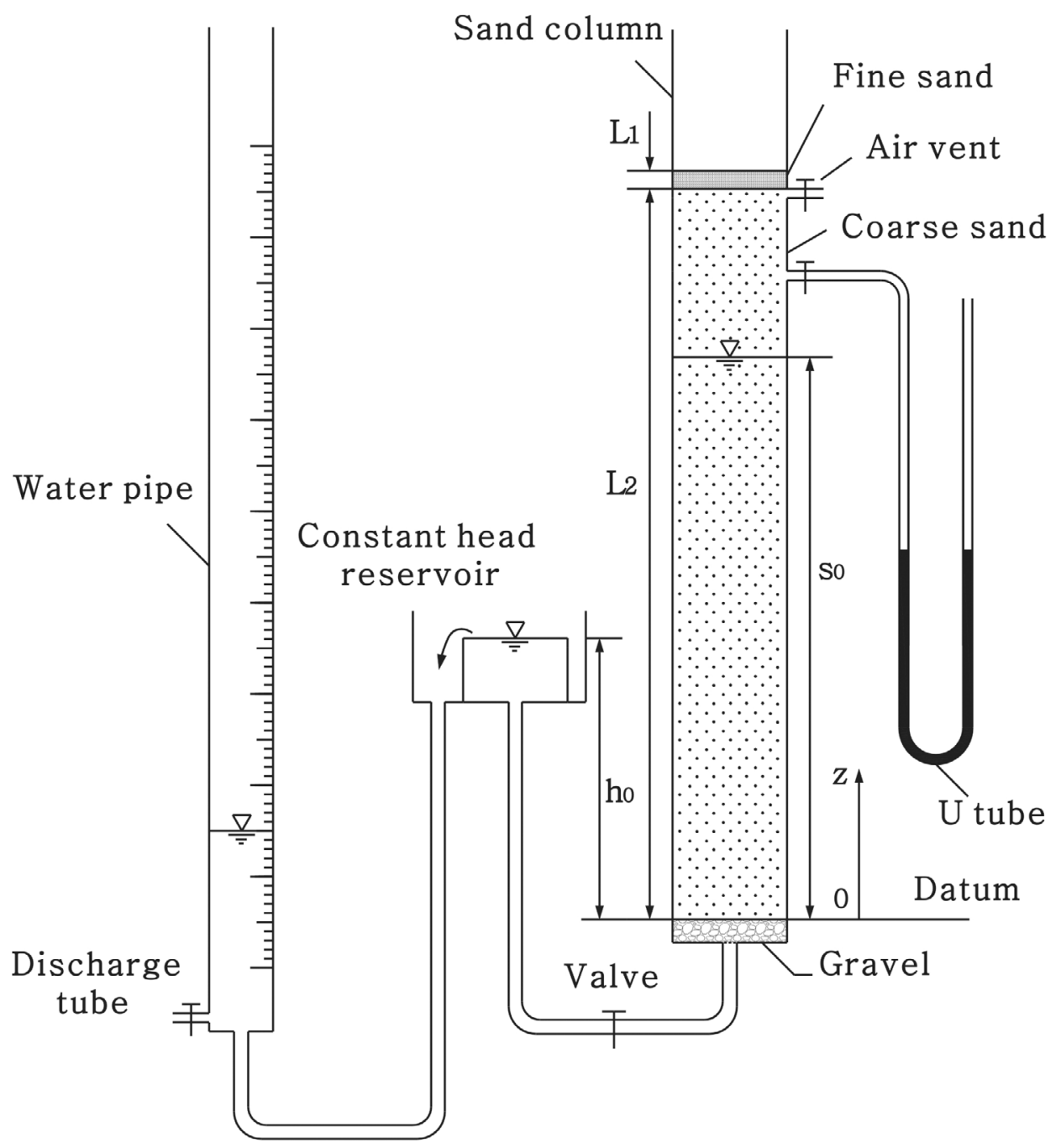

Figure 1. Schematic diagram of the sand column with and without the finer layer.

where $q_{w}$ is the rate of discharge per unit cross-sectional area, $K_{s}$ is the saturated hydraulic conductivity of the coarse sand, $h$ is the saturated column length at any given time (i.e., the position of the surface of saturation), and $h_{a}$ is the vacuum in the vadose zone expressed as a height of water column of a reference water density, which is defined as

$$
h_{a}=\frac{p_{a 0}-p_{a}}{\rho_{w 0} g}
$$

in which $p_{a 0}$ is the atmospheric pressure, $p_{a}$ is the air pressure in the vadose zone of the column, $\rho_{w 0}$ is the reference water density, and $g$ is the gravitational acceleration. It is assumed that there is no vertical air pressure gradient in the vadose zone in the coarse sand. The vertical drainage from the fine sand layer is also neglected. The rate of discharge per unit cross-sectional area is equal to the falling rate of the surface of saturation multiplied by the specific yield of the coarse sand [e.g., Ligon et al., 1962]:

$$
q_{w}=-S_{y} \frac{d h}{d t}
$$

where $S_{y}$ is the specific yield of the coarse sand, which is approximated as a constant.
[15] In order to solve for $h$, equating (2) and (4) leads to

$$
\frac{d h}{d t}=-\frac{K_{s}}{S_{y}} \frac{h-h_{a}-h_{0}}{h} .
$$

Equation (5) is the ODE describing the time variation of the surface of saturation. The initial condition is

$$
h(0)=s_{0}
$$

\subsubsection{Airflow}

[16] The governing equation for vertical one-dimensional airflow is given by generalized Darcy's law for multiphase case

$$
q_{a}=-\frac{k k_{r a}}{\mu_{a}}\left(\frac{\partial p_{a}}{\partial z}+\rho_{a} g\right)
$$

where $q_{a}$ is the volumetric flux of air, $k$ is the intrinsic permeability of the porous medium, $k_{r a}$ is the relative permeability of the porous medium to air (assumed to be a constant), $\mu_{a}$ is the dynamic viscosity of air, and $\rho_{a}$ is the density of air. Compared to the force caused by pressure gradients, the force due to gravity is much smaller so it can be neglected under 
most conditions [Charbeneau, 2000]. Hence, equation (7) can be simplified to

$$
q_{a}=-\frac{k k_{r a}}{\mu_{a}} \frac{\partial p_{a}}{\partial z}
$$

From (8), the mass flux of air for a column of cross-sectional area $A$ is [Charbeneau, 2000]

$$
m_{f}=\rho_{a} q_{a} A=-\rho_{a} A \frac{k k_{r a}}{\mu_{a}} \frac{\partial p_{a}}{\partial z} .
$$

In order to integrate (9), the equation of state $\rho_{a}\left(p_{a}\right)$ is needed. Here air is assumed to be an ideal gas. Under isothermal condition, Boyle's law holds and

$$
\rho_{a}=\rho_{a 0} \frac{p_{a}}{p_{a 0}},
$$

where $\rho_{a 0}$ is the air density at reference state (the local atmospheric condition and temperature). With the equation of state given by (10), equation (9) can be integrated from the fine sand surface to its bottom to find

$$
m_{f}=-A \frac{k k_{r a}}{\mu_{a}} \frac{\rho_{a 0}}{p_{a 0}} \frac{p_{a 0}^{2}-p_{a}^{2}}{2 L_{1}}
$$

where $L_{1}$ is the thickness of the fine sand layer, which is assumed to be relatively thin so that $k_{r a}$ can be approximated as a constant. The surface of the fine sand layer is in contact with atmosphere, so the air pressure at the surface is atmospheric pressure $p_{a 0}$. From (3),

$$
p_{a}=p_{a 0}-\rho_{w 0} g h_{a},
$$

with $h_{a}$ being a small correction term (i.e., $\rho_{w 0} g h_{a} \ll p_{a 0}$ ). Substitute (12) into (11), and expanding and keeping only the leading order term for $h_{a}$ leads to

$$
m_{f}=-A \frac{k k_{r a}}{\mu_{a}} \frac{\rho_{a 0}}{L_{1}} \rho_{w 0} g h_{a} .
$$

Equation (13) describes the air mass flux through the fine sand layer from the external atmosphere into the coarse sand layer. The minus sign indicates that the flow is downward. It should be noted that under this condition, the air mass flux $m_{f}$ is a linear function of the vacuum $h_{a}$.

[17] The mass of air in the vadose zone at any given time is

$$
m_{a}=\rho_{a} A\left(L_{2}-h\right) S_{y}
$$

Substituting the equation of state (10) into (14), and then differentiating the resulting equation with respect to $t$ leads to

$$
\frac{d m_{a}}{d t}=\frac{\rho_{a 0}}{p_{a 0}} A S_{y}\left[-p_{a} \frac{d h}{d t}+\left(L_{2}-h\right) \frac{d p_{a}}{d t}\right] .
$$

Substituting (3) into (15) leads to

$$
\frac{d m_{a}}{d t}=\frac{\rho_{a 0}}{p_{a 0}} A S_{y} \rho_{w 0} g\left[-\left(h_{a 0}-h_{a}\right) \frac{d h}{d t}-\left(L_{2}-h\right) \frac{d h_{a}}{d t}\right],
$$

where the atmospheric pressure $p_{a 0}$ is expressed as a height of water column of the reference water density, which is written as

$$
h_{a 0}=\frac{p_{a 0}}{\rho_{w 0} g} .
$$

Equation (16) is the rate of change of the air mass in the vadose zone in the column. It must be equal to the air mass flux into the column, i.e., the absolute value of (13). Hence, equating (16) and the absolute value of (13) and rearranging leads to

$$
\frac{d h_{a}}{d t}=-\frac{h_{a 0}-h_{a}}{L_{2}-h} \frac{d h}{d t}-\frac{k k_{r a}}{\mu_{a}} \frac{p_{a 0}}{L_{1} S_{y}} \frac{h_{a}}{L_{2}-h} .
$$

The derivative $d h / d t$ in the first term of the right-hand side of (18) can be replaced by (5). The resulting equation is

$$
\frac{d h_{a}}{d t}=\frac{K_{s}}{S_{y}} \frac{h_{a 0}-h_{a}}{L_{2}-h} \frac{h-h_{a}-h_{0}}{h}-\frac{k k_{r a}}{\mu_{a}} \frac{p_{a 0}}{L_{1} S_{y}} \frac{h_{a}}{L_{2}-h} .
$$

Equation (19) is the ODE describing the time variation of vacuum in the vadose zone. The initial condition is

$$
h_{a}(0)=0
$$

Equations (5) and (19) constitute the set of governing equations describing the flow of air and water.

[18] Substitute (12) into (11) and expand, and if both the terms are kept, then the air mass flux changes into

$$
m_{f}=-A \frac{k k_{r a}}{\mu_{a}} \frac{\rho_{a 0}}{L_{1}} \rho_{w 0} g h_{a}\left(1-\frac{h_{a}}{2 h_{a 0}}\right) .
$$

Equating the absolute value of (21) and (16) and then replacing $d h / d t$ by (5) leads to

$$
\frac{d h_{a}}{d t}=\frac{K_{s}}{S_{y}} \frac{h_{a 0}-h_{a}}{L_{2}-h} \frac{h-h_{a}-h_{0}}{h}-\frac{k k_{r a}}{\mu_{a}} \frac{p_{a 0}}{L_{1} S_{y}} \frac{h_{a}}{L_{2}-h}\left(1-\frac{h_{a}}{2 h_{a 0}}\right) .
$$

Then the set of governing equations becomes (5) and (22).

\subsection{Air-Water Two-Phase Flow Numerical Solution}

[19] The basic mass and energy balance equation describing air-water two-phase flow can be written in the general form [Pruess et al., 1999]

$$
\frac{d}{d t} \int_{V_{n}} M^{\kappa} d V_{n}=\int_{\Gamma_{n}} \mathbf{F}^{\kappa} \cdot \mathbf{n} d \Gamma_{n}+\int_{V_{n}} q^{\kappa} d V_{n}
$$

The integration is over an arbitrary subdomain $V_{n}$ of the flow system under study, which is bounded by the closed surface $\Gamma_{n}$. The quantity $M$ appearing in the accumulation term (left-hand side) represents mass or energy per volume, with $\kappa$ labeling the mass component of air or water. $\mathbf{F}$ denotes mass flux and $q$ denotes sinks and sources. The $\mathbf{n}$ is a normal vector on surface element $d \Gamma_{n}$, pointing inward into $V_{n}$. 
[20] The general form of the mass accumulation term is

$$
M^{\kappa}=\phi \sum_{\beta} S_{\beta} \rho_{\beta} X_{\beta}^{\kappa},
$$

where $\phi$ is porosity, $S_{\beta}$ is the saturation of phase $\beta$ (i.e., the fraction of pore volume occupied by phase $\beta$ ), $\rho_{\beta}$ is the density of phase $\beta$, and $X_{\beta}^{\kappa}$ is the mass fraction of component $\kappa$ present in phase $\beta$. The total mass of component $\kappa$ (air or water) is obtained by summing over the fluid phase $\beta$ (liquid or gas).

[21] Advective mass flux of a component (air or water) is a sum over phases, which takes the form

$$
\mathbf{F}^{\kappa}=\sum_{\beta} X_{\beta}^{\kappa} \mathbf{F}_{\beta},
$$

and individual phase fluxes are given by a multiphase version of Darcy's law:

$$
\mathbf{F}_{\beta}=\rho_{\beta} \mathbf{u}_{\beta}=-k \frac{k_{r \beta} \rho_{\beta}}{\mu_{\beta}}\left(\nabla P_{\beta}-\rho_{\beta} \mathbf{g}\right),
$$

where $\mathbf{u}_{\beta}$ is the Darcy velocity (volume flux) in phase $\beta$, $k_{r \beta}$ is relative permeability to phase $\beta, \mu_{\beta}$ is viscosity, $P_{\beta}$ is the fluid pressure in phase $\beta$, and $\mathbf{g}$ is the vector of gravitational acceleration. The pressures in liquid phase $\left(P_{l}\right)$ and gas phase $\left(P_{g}\right)$ are related via the capillary pressure $P_{c}(\leq 0)$ :

$$
P_{c}=P_{l}-P_{g}
$$

\section{Experiments}

\subsection{Experimental Setup}

[22] For saturated-unsaturated flow, a vertical column of homogeneous coarse sand was drained at its bottom at constant head. For air-water two-phase flow, a thin fine sand layer was placed at the top of the coarse sand and the column was drained in the same manner. The experimental sequence is as following: (1) falling-head test to determine the saturated hydraulic conductivity of the coarse sand; (2) constanthead drainage experiment for saturated-unsaturated flow; (3) falling-head test to determine the saturated hydraulic conductivity of the fine sand; and (4) constant-head drainage for air-water two-phase flow. In the falling-head tests, the water level in the column was observed. In the pair of constant-head drainage experiments, cumulative outflow and vacuum in the vadose zone were measured.

[23] The experimental setup consisted of a PVC pipe of $104 \mathrm{~cm}$ length and $9.5 \mathrm{~cm}$ inner diameter with coarse artificial sand to a height of $80 \mathrm{~cm}$ (Figure 1), after placing a $4.5 \mathrm{~cm}$ layer of gravel at the bottom to act as a drain. A plastic tube was placed at the bottom of the column and connected to a constant-head reservoir, the height of which can be adjusted. It was also used to saturate the column from below. Another PVC pipe (water pipe in Figure 1), $122 \mathrm{~cm}$ long and $4.2 \mathrm{~cm}$ inner diameter, was used to collect cumulative outflow of water from the column. There was another plastic tube that connected the constant-head reservoir to the water pipe. A U tube was placed $10 \mathrm{~cm}$ below the coarse sand surface to measure the vacuum in the vadose zone. The fluid in the $\mathrm{U}$ tube is tap water, which is the same as the water used to perform the drainage experiment. Two PC cameras, which are connected to different computers, were used to film the water levels in the water pipe and the $U$ tube. After the drainage experiment, data were acquired from the video files in the computer.

\subsection{Experimental Procedure}

[24] Close the valve between the $U$ tube and the column (valve 1). The column was first saturated slowly from below to a certain distance above the coarse sand surface (Figure 1). This was accomplished by raising the constant-head reservoir and adding water to it. Then close the valve at the bottom of the column (valve 2) and lower the constant-head reservoir to a specified position. Turn on one computer and one PC camera to film the water level in the column. A falling-head test began by opening valve 2 . When the water level was near the coarse sand surface, close valve 2 and save the video file.

[25] After the falling-head test, the water level in the column was lowered very slowly to $z=60 \mathrm{~cm}$ by adjusting the constant-head reservoir (Figure 1). After the water level was held at this specified height for 50 min so that the column was in hydrostatic equilibrium, close valve 2 . Lower the constanthead reservoir further to $z=30 \mathrm{~cm}$. Open valve 1 . The two $\mathrm{PC}$ cameras and computers were both used to film the water levels in the water pipe and the $U$ tube. The drainage experiment commenced at the moment when valve 2 was opened. The experiment was continued until the water level in the water pipe was static. Save the video files.

[26] When the above two experiments were completed, a fine sand layer of $2 \mathrm{~cm}$ thickness was placed on the surface of the coarse sand. To allow air to escape from the sand during saturation of the column from below, an air vent was placed in the column just below the fine sand layer (Figure 1). Close valve 1. Again, the column was saturated from below very slowly. When water came out of the air vent, close it and the saturation process continued until water level reached a specified height above the fine sand surface. The constanthead drainage experiment for air-water two-phase flow was performed. A photo of the arrangement of the equipment is shown in Figure 2. Lower the water level in the column to $z=60 \mathrm{~cm}$ by adjusting the constant-head reservoir in the same manner as described in experiment 2 . The air vent was opened when the water table dropped to below the fine sand layer. The following procedures were the same as that in experiment 2. During the experiment, the temperature was about $25^{\circ} \mathrm{C}$, and the average atmospheric pressure was about $100,439.5 \mathrm{~Pa}$.

[27] The saturated hydraulic conductivity of the fine sand was determined separately using a falling-head permeameter. The inner diameter of the permeameter is $4.5 \mathrm{~cm}$, and the sample length in the permeameter is $19.5 \mathrm{~cm}$.

[28] The soil-water characteristic curves of the fine and coarse sands were determined separately. The soil-water characteristic curve of the fine sand was measured using a pressure plate apparatus. The soil-water characteristic curve of the coarse sand was measured based on the approach described by Lei et al. [1988] due to its coarse texture. When the experiment reached equilibrium, the sample was then removed, weighed, and oven-dried to determine the water 


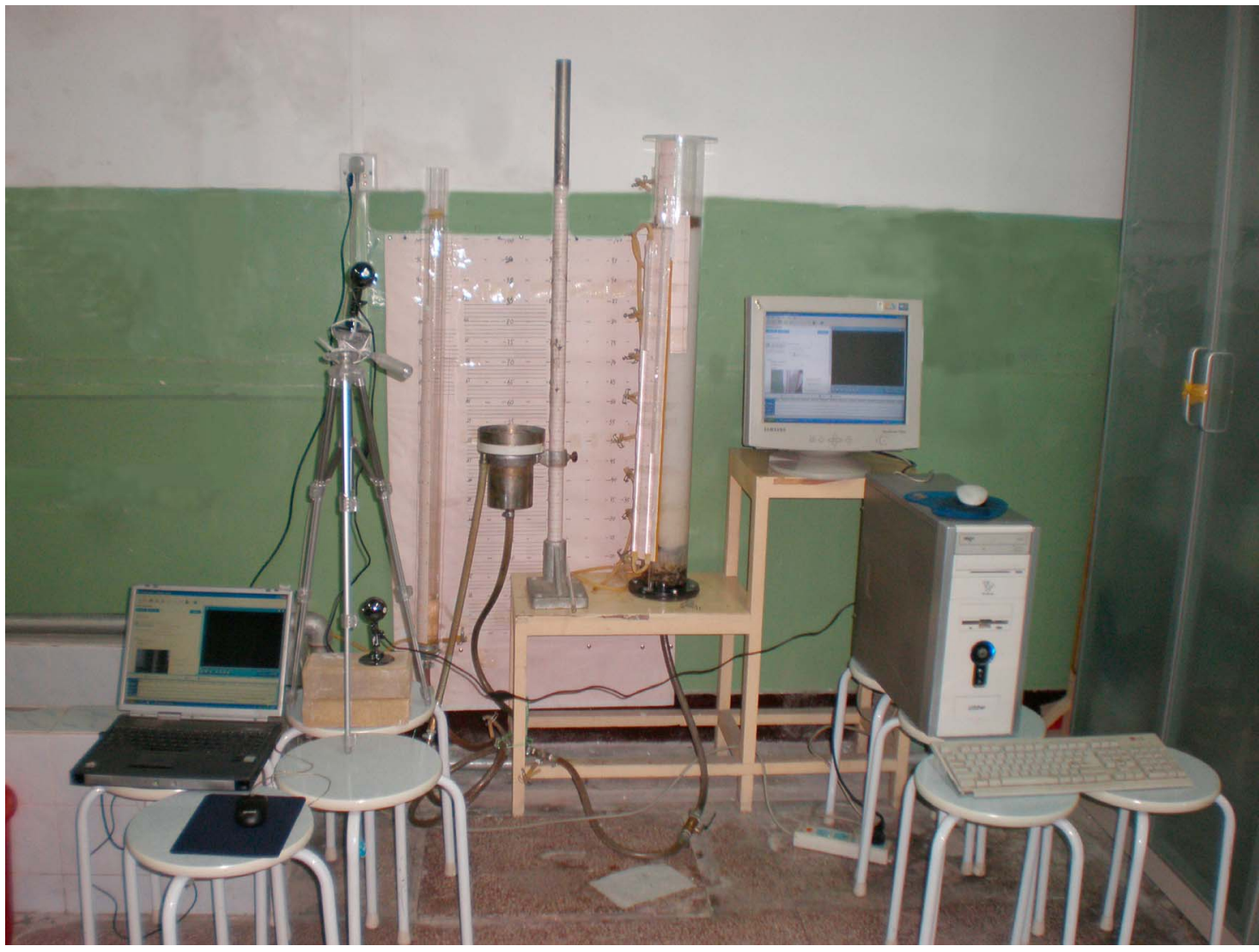

Figure 2. Arrangement of the equipment for experiment 4.

content. The bulk density of both the fine and coarse sands were also determined by the method described by Tan [2005].

\section{Numerical Methods}

\subsection{Saturated-Unsaturated Flow}

[29] The problem formulated in (1) was solved numerically by the finite difference scheme of Celia et al. [1990], which was proved to be accurate with perfect mass conservation [Celia et al., 1990; Pinder and Celia, 2006; Kosugi, 2008]. The soil-water characteristic curve for the coarse sand was chosen as the van Genuchten model [van Genuchten, 1980]

$$
\theta(\psi)= \begin{cases}\theta_{r}+\frac{\theta_{s}-\theta_{r}}{\left[1+(\alpha|\psi|)^{n}\right]^{m}}, & \psi<0 \\ \theta_{s}, & \psi \geq 0\end{cases}
$$

where $\theta_{r}$ and $\theta_{s}$ are the residual and saturated volumetric water content, respectively $\left(\mathrm{cm}^{3} / \mathrm{cm}^{3}\right), \alpha\left(>0, \mathrm{~cm}^{-1}\right)$ is related to the inverse of the air entry pressure, $n(>1)$ is a measure of the pore size distribution, and $m=1-1 / n$ [van Genuchten, 1980]. The determined bulk density of the coarse sand is $1.65 \mathrm{~g} / \mathrm{cm}^{3}$. The measured water content was converted to volumetric water content by considering the bulk density. The values of the parameters were determined using the Marquardt-Levenberg algorithm, which is an algorithm for least squares estimation of nonlinear parameters. The fitted parameters are $\theta_{r}=0.0235, \theta_{s}=0.314, \alpha=0.0684 \mathrm{~cm}^{-1}$, and $n=5.625$. The measured and fitted soil-water characteristic curves are shown in Figure 3. The unsaturated hydraulic conductivity was specified as the van Genuchten-Mualem (VGM) model [Mualem, 1976; van Genuchten, 1980]

$$
K(\psi)= \begin{cases}K_{s} \frac{\left\{1-(\alpha|\psi|)^{n-1}\left[1+(\alpha|\psi|)^{n}\right]^{-m}\right\}^{2}}{\left[1+(\alpha|\psi|)^{n}\right]^{m / 2}}, & \psi<0 \\ K_{s}, & \psi \geq 0\end{cases}
$$

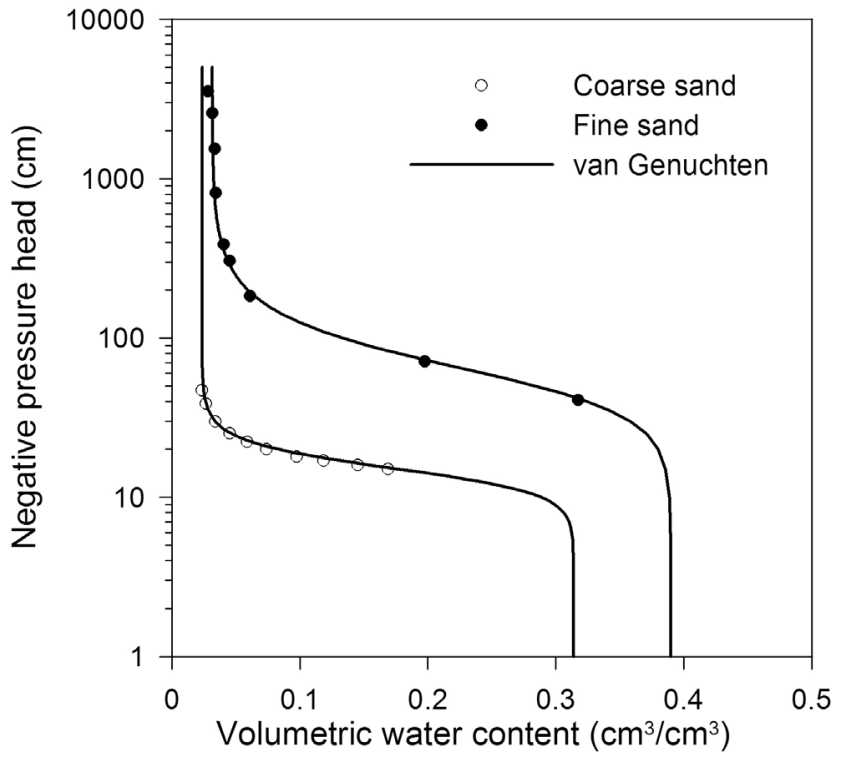

Figure 3. Soil water characteristic curves for the coarse and fine sands. 


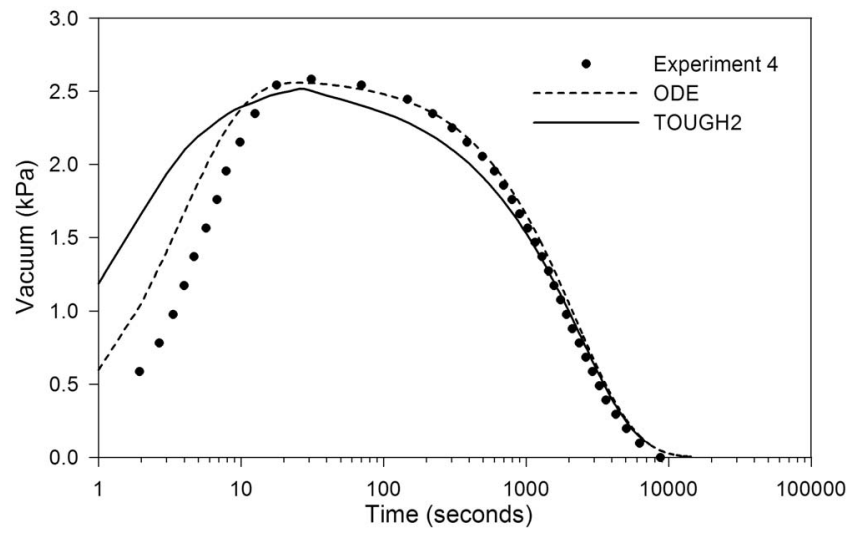

Figure 4. Comparison of observed and calculated vacuum in the vadose zone of the column in experiment 4 .

where $K_{s}=0.07423 \mathrm{~cm} / \mathrm{s}$ is the saturated hydraulic conductivity of the coarse sand determined by experiment 1 .

[30] The column was discretized into 161 nodes with nodal spacing $\Delta z=0.5 \mathrm{~cm}$. The fist node is at the bottom of the column, and the last one is at the upper surface of the coarse sand. The constant time step is $\Delta t=1 \mathrm{~s}$. The geometric mean for internodal hydraulic conductivities is used herein [e.g., Haverkamp and Vauclin, 1979; Szymkiewicz, 2009]. The convergence criterion is chosen as that of Huang et al. [1996] with $\delta_{r}=0.0001$ and $\delta_{a}=10^{-7}$. Numerical simulation was carried out by writing a computer program, called OSUNF, in Visual Basic for Application (VBA) based on Microsoft Excel 2003.

\subsection{Air-Water Two-Phase Flow Numerical Solution}

[31] The numerical simulations of the air-water two-phase flow drainage experiment were carried out using the EOS3 module of TOUGH2, a general-purpose numerical simulator for multidimensional fluid and heat flows of multiphase, multicomponent fluid mixtures in porous and fractured media [Pruess et al., 1999]. The soil-water characteristic curve for the fine sand was also chosen as the van Genuchten model, i.e., Equation (28). The determined bulk density of the fine sand is $1.59 \mathrm{~g} / \mathrm{cm}^{3}$. The fitted parameters are $\theta_{r}=0.0315$, $\theta_{s}=0.39, \alpha=0.0177 \mathrm{~cm}^{-1}$, and $n=3.0086$. Figure 3 shows the measured and fitted soil-water characteristic curves. The saturated hydraulic conductivity of the fine sand determined by experiment 3 is $0.004292 \mathrm{~cm} / \mathrm{s}$. The relative water permeability for both sands was chosen as the VGM model

$$
k_{r w}\left(S_{e}\right)=\left\{\begin{array}{ll}
S_{e}^{1 / 2}\left[1-\left(1-S_{e}^{1 / m}\right)^{m}\right]^{2} & S_{w}<S_{w s} \\
1 & S_{w} \geq S_{w s}
\end{array},\right.
$$

where $S_{e}=\left(S_{w}-S_{w r}\right) /\left(S_{w s}-S_{w r}\right)$, is the effective water saturation, $S_{w}$ is the water saturation, and $S_{w r}$ and $S_{w s}$ are the residual and saturated water saturation, respectively. The relative air permeability for both sands was specified as [Pruess et al., 1999]

$$
k_{r a}\left(S_{e}^{*}\right)=\left(1-S_{e}^{*}\right)^{2}\left(1-S_{e}^{* 2}\right),\left(S_{a r}>0\right)
$$

where $S_{e}^{*}=\left(S_{w}-S_{w r}\right) /\left(1-S_{w r}-S_{a r}\right)$, and $S_{a r}$ is the residual air saturation, the default value of $S_{a r}=0.1$ was used for both the fine and coarse sands in the TOUGH2 simulations.
[32] The column was discretized into 164 elements with spacing $\Delta z=0.5 \mathrm{~cm}$. The boundary conditions were atmospheric pressure and no flow of water at the top of the column and a water pressure of $30 \mathrm{~cm}$ of water and no flow of air at the bottom of the column. The column was initially in hydrostatic equilibrium. The initial water table was $20 \mathrm{~cm}$ below the coarse sand surface, i.e., at $z=60 \mathrm{~cm}$.

\subsection{Solutions of ODE for Air-Water Two-Phase Flow}

[33] In order to solve the ODE, the relative air permeability value $k_{r a}$ has to be estimated. The water saturation at the interface $(z=80 \mathrm{~cm})$ is higher than that at the fine sand surface $(z=82 \mathrm{~cm})$. So the relative air permeability $k_{r a}$ is lower at the interface than at the fine sand surface. The airflow into the column is mostly controlled by this lower $k_{r a}$. Then it is reasonable to use the fine sand water saturation at the interface to calculate the $k_{r a}$ value. The VGM model for relative air permeability [Parker et al., 1987] was chosen for the fine sand to calculate the $k_{r a}$ value

$$
k_{r a}\left(S_{e}\right)=\left(1-S_{e}\right)^{1 / 2}\left(1-S_{e}^{1 / m}\right)^{2 m}
$$

The capillary pressure head at the interface is $\psi=-20 \mathrm{~cm}$. Substituting $\psi$ into (28), calculating $S_{e}$ with $S_{w s}=1$, and then substituting $S_{e}$ into (32) leads to $k_{r a}=0.00245$.

[34] The specific yield of the coarse sand is calculated as

$$
S_{y}=\frac{V_{m}}{A\left(s_{0}-h_{0}\right)},
$$

where $V_{m}$ is the cumulative volume of outflow at the end of experiment 2. With the value of $V_{m}=581.7 \mathrm{~cm}^{3}$, the specific yield is $S_{y}=0.2736$.

[35] The sets of ODE were solved numerically by the fourth-order Runge-Kutta method using variable time steps $[X u, 2006]$ with an initial time step $\Delta t=1 \mathrm{~s}$. A minimum time step was set as $\Delta t_{\min }=10^{-6} \mathrm{~s}$, when the time step during computing is less than $\Delta t_{\min }$, and then the computing is terminated. The convergence criterion is chosen as $10^{-5} \mathrm{~m}$. Numerical calculations were carried out using the program of $X u$ [2006] with some modifications to account for this specific problem.

\section{Results and Discussion}

\subsection{Vacuum and Cumulative Outflow}

[36] During the saturated-unsaturated flow drainage experiment (experiment 2), no vacuum in the vadose zone of the column was observed in the $U$ tube. This means that under this condition, the air pressure in the column was almost the same as the external atmospheric pressure. Air can flow freely from the atmosphere into the column due to the coarse texture of the sand. Hence, the drainage of water from the coarse sand was quick. Most of the water was already drained in the first $500 \mathrm{~s}$.

[37] During the air-water two-phase flow drainage experiment (experiment 4), significant vacuum was observed. The vacuum in the vadose zone of the column increased very fast, from 0 to $2.54 \mathrm{kPa}(26 \mathrm{~cm}$ of water column) at $18 \mathrm{~s}$ since the drainage started, and reached a maximum value of $2.58 \mathrm{kPa}$ (26.4 cm of water column) at $31 \mathrm{~s}$, then gradually returned to zero. After $8700 \mathrm{~s}$, the air pressure in the vadose zone was 


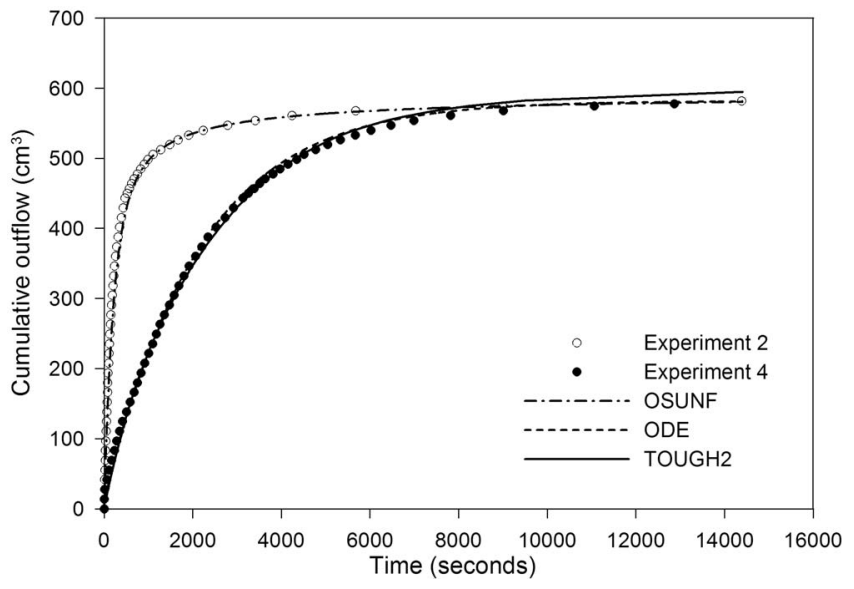

Figure 5. Comparison between theoretical and experimental cumulative outflow.

almost equal to the atmospheric pressure. The drainage of water was slow because water was held in by the vacuum and could not drain freely.

[38] The calculated $k_{r a}=0.00245$ was first substituted into the set of ODE to obtain a solution. Then its value was adjusted to obtain the best fitting between theoretical and experimental data. A comparison of the measured vacuum in experiment 4 and the solution of ODE of (5) and (19) with a fitted $k_{r a}=0.00136$ is shown in Figure 4. The agreement between the solution of ODE and the experimental data is satisfactory except for the earlier stage of drainage (less than 20 s). Vacuum was also calculated using TOUGH2, and the best result is also shown in Figure 4. The agreement between the TOUGH 2 simulation and the experimental data, however, is not so good.

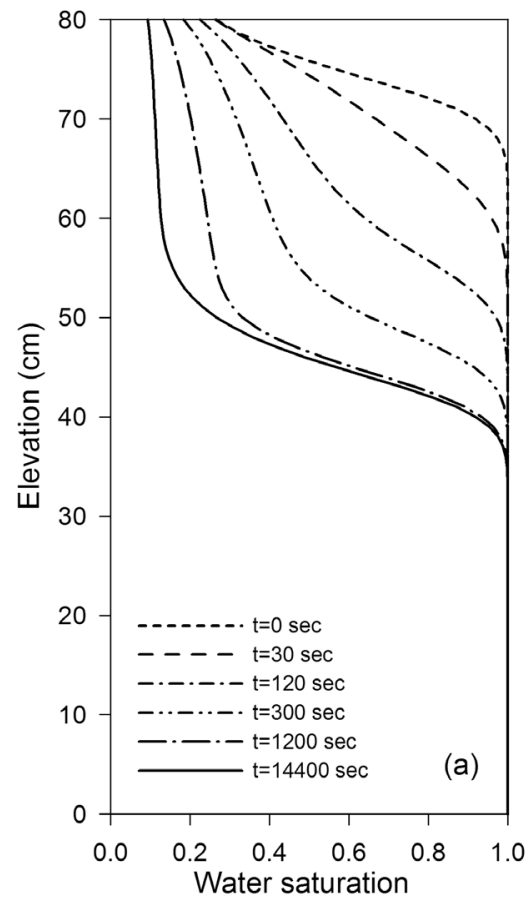

[39] In the earlier stage, both the solution of ODE and the TOUGH2 simulation give results noticeably higher than the experimental values. This difference may be caused by the following reasons. First, the volume of air in the left branch of the U tube above the water level (Figure 1) is not negligible compared to the initial volume of air in the vadose zone. This volume of air was not considered both in the solution of ODE and in the TOUGH2 simulation. Second, the air pressure in the vadose zone changes very fast in this stage, which may not be instantaneously reflected by the water level in the $U$ tube. Thus, the measured vacuum may be lower than the true vacuum in the vadose zone.

[40] The cumulative outflow $V_{w}$ in the saturatedunsaturated flow OSUNF simulation and air-water two phase flow TOUGH2 simulation at any given time is calculated as

$$
V_{w}=\sum_{i=1}^{N-1}\left(\frac{\theta_{i}^{0}+\theta_{i+1}^{0}}{2}-\frac{\theta_{i}^{j}+\theta_{i+1}^{j}}{2}\right) A \Delta z,
$$

where $N$ is the total number of nodes and $\theta^{0}$ and $\theta^{j}$ are the volumetric water content at $t=0$ and time level $j$, respectively. For the air-water two-phase flow ODE solutions, the cumulative outflow at any given time is calculated as follows:

$$
V_{w}=A\left(s_{0}-h\right) S_{y} .
$$

[41] Figure 5 shows a comparison between the theoretical and experimental cumulative outflow for experiments 2 and 4. Excellent agreement is achieved for both experiments. For the air-water two-phase flow drainage, the flow regime is significantly altered by the fine sand layer, as indicated by the data of the two experiments. The cumulative volume of outflow in experiment 4 is much less than that of experiment 2 until $3 \mathrm{~h}(10,800 \mathrm{~s})$ after the drainage began.

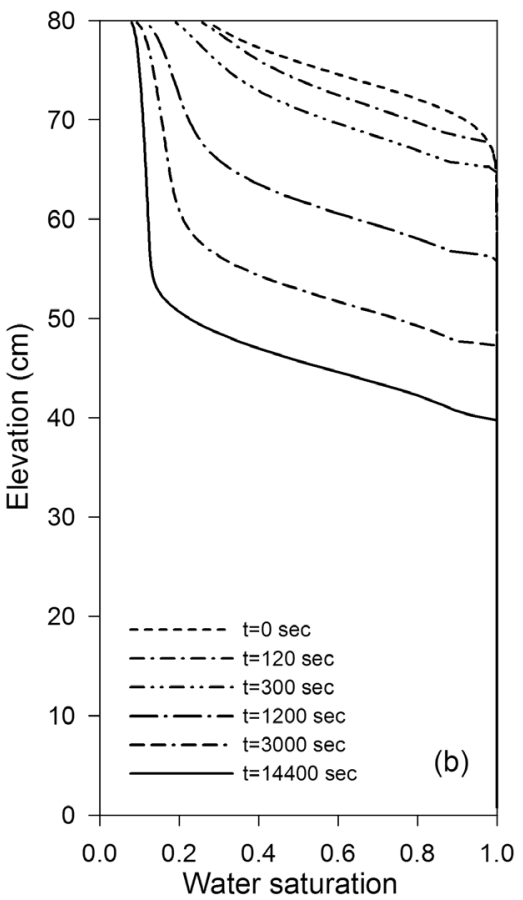

Figure 6. Temporal water saturation profiles with elevation above the datum for (a) experiment 2 and (b) experiment 4. 


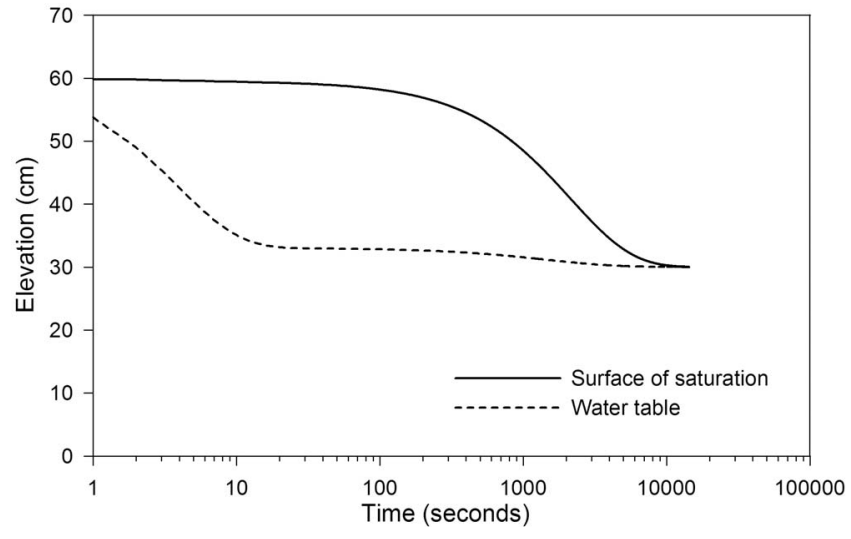

Figure 7. Time evolution of the surface of saturation and the water table in experiment 4.

[42] For experiment 4, both the solutions based on TOUGH2 and equations (5) and (19) match well with the experimental data. A careful examination of the curves shows that the solution based on (5) and (19) is slightly better than TOUGH2.

[43] Generally, when fluids are drained from porous media, the theory of saturated-unsaturated flow should be used. However, in the air-water two-phase flow drainage, although the drainage of water at the water table was assumed to be instantaneous and complete in the approximate solution based on (5) and (19), the solution can capture the details of the drainage process, as demonstrated by the good agreement between the observed pressure and that calculated using the equations (5) and (19) for experiment 4. This is mainly due to the vacuum in the vadose zone, which decreased the rate of discharge.

[44] In the saturated-unsaturated flow numerical simulation, the specific storage of the medium was also considered. When a value of $S_{S}=10^{-6} \mathrm{~m}^{-1}$ [Clement et al., 1994] was chosen, no visual difference can be found in the cumulative outflow (data not shown), suggesting that $S_{S}$ can be neglected and that equation (1a) for the general saturated-unsaturated flow is appropriate.

\subsection{Water Saturation Profile}

[45] Figure 6 shows the vertical water saturation profiles at different times simulated using OSUNF for experiment 2 and TOUGH2 for experiment 4. Figure 6 a shows that at

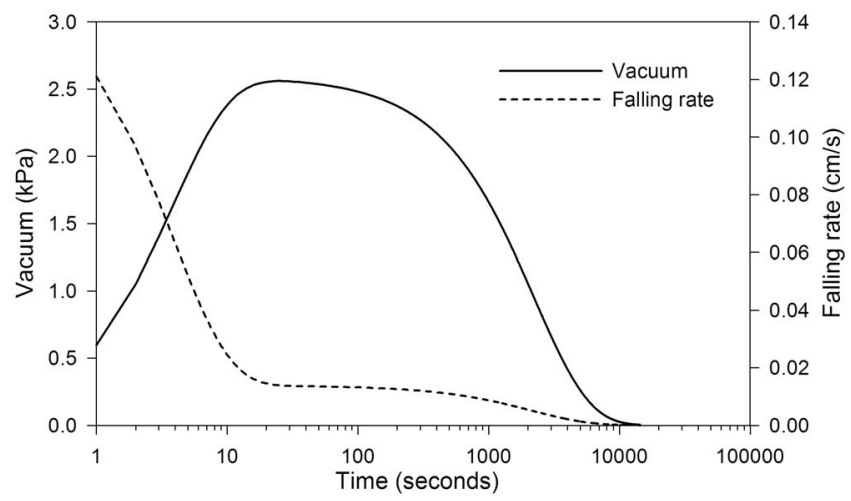

Figure 8. Time evolution of the vacuum and the falling rate of the surface of saturation in experiment 4 .

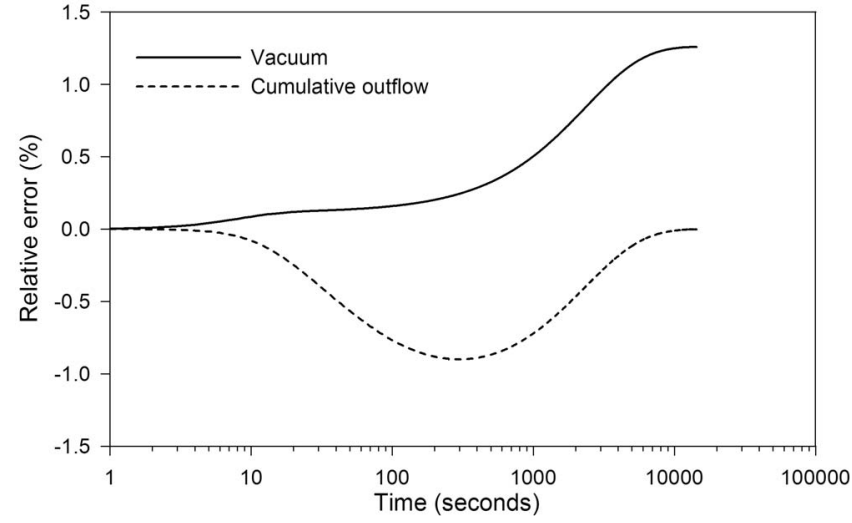

Figure 9. The relative error caused by keeping only the leading-order term.

earlier times there is a substantial amount of water in the vadose zone. As time progresses, the water saturation profile becomes closer to the steady state profile, which corresponds to the soil-water characteristic curve of the coarse sand. Figure $6 \mathrm{~b}$ shows that after the fine sand layer was placed, the time evolution of the water saturation profile is substantially different from Figure 6a. Clearly, the existence of the fine sand layer greatly restricted the movement of air from the atmosphere into the sand column. Water was held in by the vacuum and could not drain freely by gravity.

\subsection{On the Solutions of ODE for Air-Water Two-Phase Flow}

\subsubsection{Surface of Saturation and Water Table}

[46] Since the solution of ODE gives better results than TOUGH2, it is used to analyze the drainage process of experiment 4 . Figure 7 shows the time evolution of the surface of saturation and the water table calculated by the solution of ODE using (5) and (19). The water table is defined as the surface on which the pressure is atmospheric [e.g., Bear, 1972]. Before the drainage starts, the surface of saturation and the water table are at the same position. While the falling of the surface of saturation is very slow and gentle, the water table dropped very quickly from the initial position to near the constant-head boundary after about $10 \mathrm{~s}$. This explains the slow drainage of water from the column. At any given time, the difference between the position of the surface of saturation and the water table is the water column held in by the vacuum. It should be noted that in (4), the hydraulic head is subtracted by the vacuum $h_{a}$. The presence of the vacuum decreased the hydraulic gradient.

\subsubsection{Vacuum and Falling Rate of Surface of Saturation}

[47] Figure 8 shows the relationship between vacuum and the falling rate of the surface of saturation. At the earlier stage of drainage (less than $10 \mathrm{~s}$ ), the surface of saturation falls very quickly. At the same time, vacuum in the vadose zone increases significantly. The vacuum reaches its maximum when the falling rate of the surface of saturation becomes very low. The vacuum drops to zero when the falling rate of the surface of saturation gradually becomes zero. This conclusion is similar to that of Jiao and $\mathrm{Li}$ [2004] in their discussion on tide-induced air pressure fluctuation and that of Jiao and Guo [2009] in their discussion on pumping-induced airflow. 


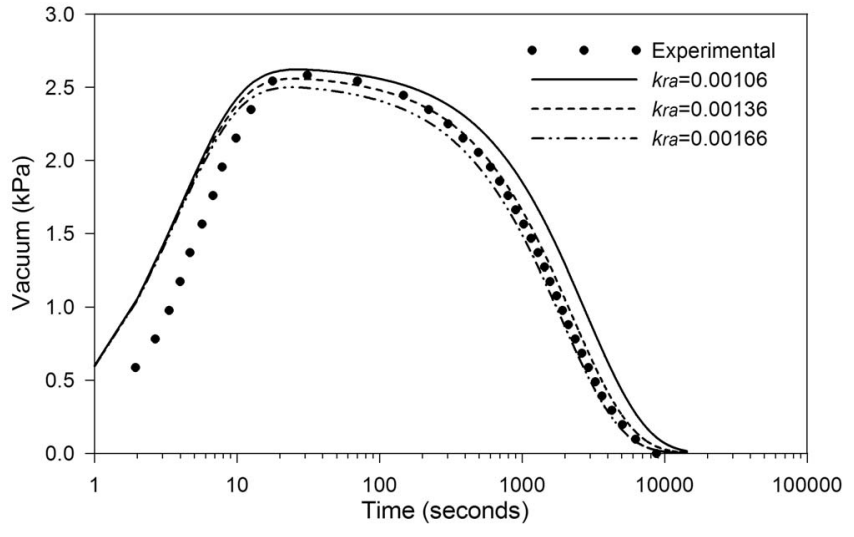

Figure 10. Theoretical results of the vacuum for different relative air permeability values compared with experimental results.

\subsubsection{Comparison of Solutions Using (19) and (22)}

[48] Figure 9 shows the relative error caused by keeping only the leading-order term for $h_{a}$ in deriving the air mass flux $m_{f}$. The relative error is calculated as the value using (22) minus the value using (19) and then divideding by the value using (19), expressed as a percentage. From Figure 9, when (19) is used, the vacuum is always smaller than that using (22). The relative error reaches a maximum value of $1.24 \%$ at the end of the drainage. Since the vacuum is smaller, the drainage of water from the column is faster. The relative error in cumulative outflow reaches a maximum value of $0.87 \%$ after $300 \mathrm{~s}$. Clearly, the relative error is very small, suggesting that keeping only the leading-order term does not cause significant error. This can be also seen from comparing (19) and (22). The two equations are identical except the brackets on the right-hand side of (22), which is almost 1 because $h_{a} / 2 h_{a 0}$ is much less than 1 .

\subsubsection{Impact of Relative Air Permeability on Vacuum and Cumulative Outflow}

[49] The relative air permeability $k_{r a}$ is the only adjustable parameter in the approximate solutions and is assumed to be a constant. This may lead to some error, because physically, its value changes with time as the water content of the fine sand layer decreases. However, as shown in Figures 5 and 6,

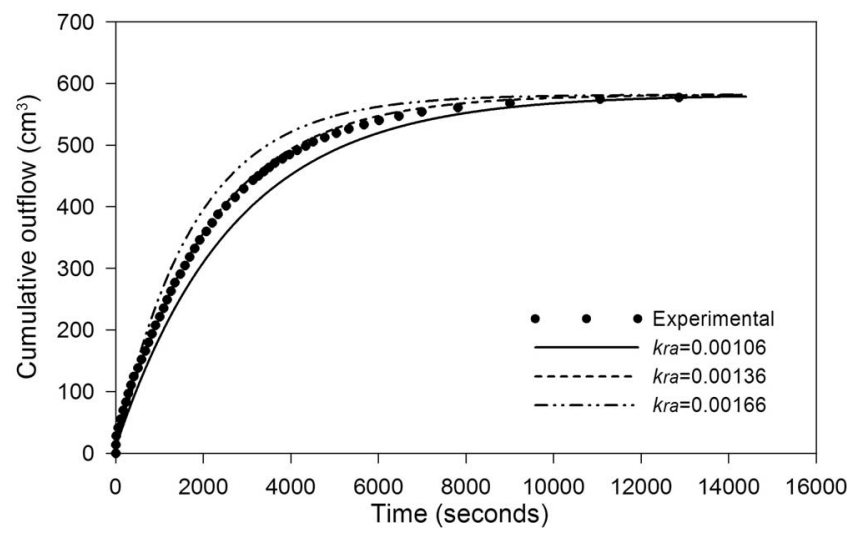

Figure 11. Theoretical results of the cumulative outflow for different relative air permeability values compared with experimental results.

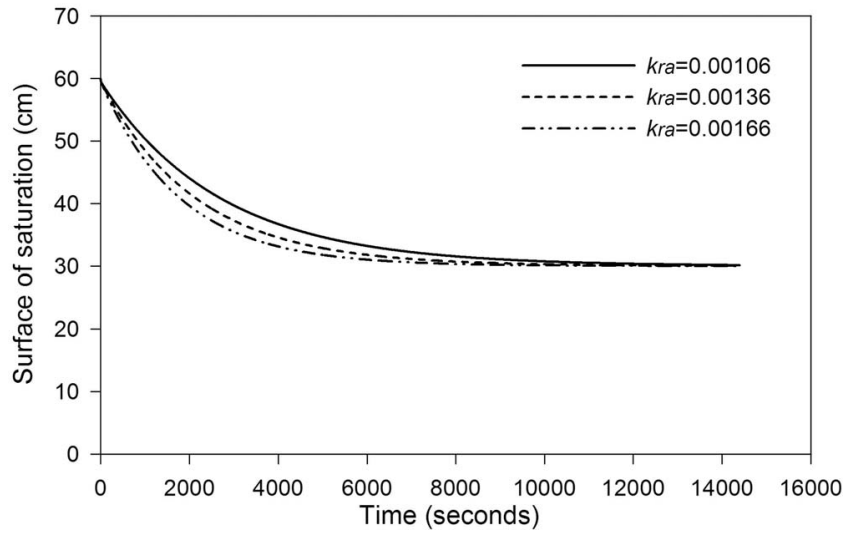

Figure 12. Theoretical results of the surface of saturation for different relative air permeability values.

a constant value is reasonable because the vacuum and cumulative outflow calculated from the solution of ODE using a constant $k_{r a}$ fit well with observed data.

[50] In the calculation, the value of $k_{r a}$ was adjusted to obtain a best fit. In order to show the impact of different values of $k_{r a}$ on theoretical results, three different values were chosen to calculate vacuum and cumulative outflow, as are shown in Figures 10 and 11. It can be clearly seen from Figure 10 that the smaller the value, the larger the vacuum. The physical meaning of this parameter is that it controls the flow of air into the column through fine sand. When $k_{r a}$ is lower, the flow of air into the column through the fine sand layer is more difficult, and hence a larger vacuum will be generated. Subsequently, the drainage of water is slower, as shown in Figure 11. Figure 12 shows how the location of the surface of saturation changes with time for different values of $k_{r a}$.

\section{Summary and Conclusions}

[51] The drainage of water from a vertical sand column with and without a fine sand layer was studied experimentally and theoretically to investigate the impact of airflow. Both a saturated-unsaturated flow drainage experiment without the fine sand layer on the top of the coarse sand and an air-water two-phase flow drainage experiment with the fine sand layer were performed. Temporal changes of vacuum and cumulative outflow were observed. While there was practically no vacuum without the fine sand layer, significant vacuum was observed with the fine sand layer. The vacuum increased quickly at the earlier time, reached a maximum, and then gradually dropped to zero. Because of the suction of the vacuum, the cumulative outflow with the fine sand layer was much smaller than that without the layer during most of the drainage process.

[52] On the basis of the mixed form of the Richards' equation and a finite difference scheme, a VBA program was developed to perform the numerical simulation of the saturated-unsaturated flow drainage experiment. Ordinary differential equations were derived to describe the air-water two-phase flow drainage experiment. After comparing with the observed data, the performance of the solutions of ODE is very satisfactory and much better than TOUGH2. Theoretical analyses based on solutions of ODE show that the surface of 
saturation in the column is much higher than the water table during most of the drainage process because of the effect of the vacuum. The vacuum in the vadose zone is closely related to the falling rate of the surface of saturation.

[53] Advantages accrue from using the ODE rather than the partial differential equations. All parameters in the ODE are constants and can be determined quickly and accurately. It requires only saturated hydraulic properties of the porous medium. The only parameter that needs to be adjusted is the relative air permeability. Furthermore, use of the RungeKutta method precludes the need for iteration with the ODE. When partial differential equations are used, a system of nonlinear equations is generated which are solved iteratively. It may be concluded that the ordinary differential equation techniques described here are valuable tools in the case of one-dimensional, vertical, part unsaturated and part saturated air-water two-phase flow problems.

[54] Acknowledgments. The authors thank Zhenlei Yang for providing the atmospheric pressure observation data. We also thank the anonymous reviewers for their very helpful comments. The study was partially supported by the Research Grants Council of the Hong Kong Special Administrative Region, China (HKU 701908P). TOUGH2 was run via the interface of PetraSim.

\section{References}

Aggelopoulos, C. A., and C. D. Tsakiroglou (2009), A multi-flowpath model for the interpretation of immiscible displacement experiments in heterogeneous soil columns, J. Contam. Hydrol., 105, 146-160, doi:10.1016/j.jconhyd.2008.12.004.

Allen, M. B., and C. L. Murphy (1986), A finite-element collocation method for variably saturated flow in two space dimensions, Water Resour. Res., 22(11), 1537-1542, doi:10.1029/WR022i011p01537.

Amaziane, B., M. Jurak, and A. Ž. Keko (2010), Modeling and numerical simulations of immiscible compressible two-phase flow in porous media by the concept of global pressure, Transp. Porous Media, 84(1), 133-152, doi:10.1007/s11242-009-9489-8.

Arbhabhirama, A., and Z. U. Ahmed (1973), Approximate solutions for nonsteady column drainage, Water Resour. Res., 9(2), 401-407, doi:10.1029/WR009i002p00401

Babajimopoulos, C. (2000), Revisiting the Douglas-Jones method for modelling unsaturated flow in a cultivated soil, Environ. Model. Softw., 15, 303-312, doi:10.1016/S1364-8152(00)00019-0.

Bear, J. (1972), Dynamics of Fluids in Porous Media, Elsevier, New York.

Bouwer, H., and R. C. Rice (1978), Delayed aquifer yield as a phenomenon of delayed air entry, Water Resour. Res., 14(6), 1068-1074, doi:10.1029/ WR014i006p01068.

Buckley, S. E., and M. C. Leverett (1942), Mechanism of fluid displacement in sands, Trans. AIME, 146, 107-116.

Casulli, V., and P. Zanolli (2010), A nested Newton-type algorithm for finite volume methods solving Richards' equation in mixed form, SIAM J. Sci. Comput., 32(4), 2255-2273, doi:10.1137/100786320.

Celia, M. A., and P. Binning (1992), A mass conservative numerical solution for two-phase flow in porous media with application to unsaturated flow, Water Resour. Res., 28(10), 2819-2828, doi:10.1029/92WR01488.

Celia, M. A., L. R. Ahuja, and G. F. Pinder (1987), Orthogonal collocation and alternating-direction procedures for unsaturated flow problems, $A d v$. Water Resour., 10(4), 178-187, doi:10.1016/0309-1708(87)90027-3.

Celia, M. A., E. T. Bouloutas, and R. L. Zarba (1990), A general massconservative numerical solution for the unsaturated flow equation, Water Resour. Res., 26(7), 1483-1496, doi:10.1029/WR026i007p01483.

Charbeneau, R. J. (2000), Groundwater Hydraulics and Pollutant Transport, Prentice-Hall, Upper Saddle River, N. J.

Class, H., R. Helmig, and P. Bastian (2002), Numerical simulation of nonisothermal multiphase multicomponent processes in porous media. 1. An efficient solution technique, Adv. Water Resour., 25, 533-550, doi:10.1016/S0309-1708(02)00014-3.

Clement, T. P., W. R. Wise, and F. J. Molz (1994), A physically based, two-dimensional, finite-difference algorithm for modeling variably saturated flow, J. Hydrol., 161, 71-90, doi:10.1016/0022-1694(94)90121-X.
Cueto-Felgueroso, L., and R. Juanes (2008), Nonlocal interface dynamics and pattern formation in gravity-driven unsaturated flow through porous media, Phys. Rev. Lett., 101(24), 244504, doi:10.1103/PhysRevLett.101. 244504.

Faust, C. R. (1985), Transport of immiscible fluids within and below the unsaturated zone: A numerical model, Water Resour. Res., 21(4), 587-596, doi:10.1029/WR021i004p00587.

Faust, C. R., J. H. Guswa, and J. W. Mercer (1989), Simulation of threedimensional flow of immiscible fluids within and below the unsaturated zone, Water Resour. Res., 25(12), 2449-2464, doi:10.1029/ WR025i012p02449.

Fokas, A. S., and Y. C. Yortsos (1982), On the exactly solvable equation $S_{t}=\left[(\beta S+\gamma)^{-2} S_{x}\right]_{x}+\alpha(\beta S+\gamma)^{-2} S_{x}$ occurring in two-phase flow in porous media, SIAM J. Appl. Math., 42(2), 318-332, doi:10.1137/ 0142025.

Fučík, R., J. Mikyška, M. Beneš, and T. H. Illangasekare (2007), An improved semi-analytical solution for verification of numerical models of two-phase flow in porous media, Vadose Zone J., 6, 93-104, doi:10.2136/vzj2006.0024.

Fujioka, Y., and T. Kitamura (1964), Approximate solution of a vertical drainage problem, J. Geophys. Res., 69(24), 5249-5255, doi:10.1029/ JZ069i024p05249.

Guarnaccia, J., G. F. Pinder, and M. Fishman (1997), NAPL: Simulator documentation, EPA/600/SR-97/102, Natl. Risk Manage. Lab., U.S. Environ. Prot. Agency, Ada, Okla.

Guo, H.-P., and J. J. Jiao (2008), Numerical study of airflow in the unsaturated zone induced by sea tides, Water Resour. Res., 44, W06402, doi:10.1029/2007WR006532.

Guo, H., J. J. Jiao, and E. P. Weeks (2008), Rain-induced subsurface airflow and Lisse effect, Water Resour. Res., 44, W07409, doi:10.1029/ 2007WR006294.

Haverkamp, R., and M. Vauclin (1979), A note on estimating finite difference interblock hydraulic conductivity values for transient unsaturated flow problems, Water Resour. Res., 15(1), 181-187, doi:10.1029/ WR015i001p00181.

Hillel, D. (1980), Fundamentals of Soil Physics, Academic, San Diego, Calif.

Hogarth, W. L., and J. Y. Parlange (2000), Application and improvement of a recent approximate analytical solution of Richards' equation, Water Resour. Res., 36(7), 1965-1968, doi:10.1029/2000WR900042.

Hornberger, G. M., and I. Remson (1970), A moving boundary model of a one-dimensional saturated-unsaturated, transient porous flow system, Water Resour. Res., 6(3), 898-905, doi:10.1029/WR006i003p00898.

Hoteit, H., and A. Firoozabadi (2008), Numerical modeling of two-phase flow in heterogeneous permeable media with different capillarity pressures, Adv. Water Resour., 31, 56-73, doi:10.1016/j.advwatres.2007.06.006.

Huang, K., B. P. Mohanty, and M. T. van Genuchten (1996), A new convergence criterion for the modified Picard iteration method to solve the variably saturated flow equation, $J$. Hydrol., 178, 69-91, doi:10.1016/ 0022-1694(95)02799-8.

Jiao, J. J., and H. Guo (2009), Airflow induced by pumping tests in unconfined aquifer with a low-permeability cap, Water Resour. Res., 45, W10445, doi:10.1029/2009WR007760.

Jiao, J. J., and H. Li (2004), Breathing of coastal vadose zone induced by sea level fluctuations, Geophys. Res. Lett., 31, L11502, doi:10.1029/ 2004GL019572.

Juncu, G., A. Nicola, and C. Popa (2010), Nonlinear multigrid methods for numerical solution of the unsaturated flow equation in two space dimensions, Transp. Porous Media, 83(3), 637-652, doi:10.1007/s11242-0099465-3.

Kavetski, D., P. Binning, and S. W. Sloan (2002), Noniterative time stepping schemes with adaptive truncation error control for the solution of Richards equation, Water Resour. Res., 38(10), 1211, doi:10.1029/ 2001WR000720.

Kirkland, M. R., R. G. Hills, and P. J. Wierenga (1992), Algorithms for solving Richards' equation for variably saturated soils, Water Resour. Res., 28(8), 2049-2058, doi:10.1029/92WR00802.

Kosugi, K. (2008), Comparison of three methods for discretizing the storage term of the Richards equation, Vadose Zone J., 7(3), 957-965, doi:10.2136/vzj2007.0178.

Kroszynski, U. (1975), Flow in a vertical porous column drained at its bottom at constant flux, J. Hydrol., 24, 135-153, doi:10.1016/00221694(75)90147-X.

Kueper, B. H., and E. O. Frind (1991a), Two-phase flow in heterogeneous porous media: 1. Model development, Water Resour. Res., 27(6), 1049-1057, doi:10.1029/91WR00266. 
Kuppusamy, T., J. Sheng, J. C. Parker, and R. J. Lenhard (1987), Finiteelement analysis of multiphase immiscible flow through soils, Water Resour. Res., 23(4), 625-631, doi:10.1029/WR023i004p00625.

Lei, Z., S. Yang, and S. Xie (1988), Soil Water Dynamics (in Chinese), Tsinghua Univ. Press, Beijing.

Li, H., and J. J. Jiao (2005), One-dimensional airflow in unsaturated zone induced by periodic water table fluctuation, Water Resour. Res., 41, W04007, doi:10.1029/2004WR003916.

Ligon, J. T., H. P. Johnson, and D. Kirkham (1962), Unsteady-state drainage of fluid from a vertical column of porous material, J. Geophys. Res., 67(13), 5199-5204, doi:10.1029/JZ067i013p05199.

McWhorter, D. B., and D. K. Sunada (1990), Exact integral solutions for two-phase flow, Water Resour. Res., 26(3), 399-413, doi:10.1029/ WR026i003p00399.

Menziani, M., S. Pugnaghi, and S. Vincenzi (2007), Analytical solutions of the linearized Richards equation for discrete arbitrary initial and boundary conditions, J. Hydrol., 332, 214-225, doi:10.1016/j.jhydrol.2006.06.030.

Miller, C. T., G. Christakos, P. T. Imhoff, J. F. McBride, J. A. Pedit, and J. A. Trangenstein (1998), Multiphase flow and transport modeling in heterogeneous porous media: Challenges and approaches, Adv. Water Resour., 21(2), 77-120, doi:10.1016/S0309-1708(96)00036-X.

Morel-Seytoux, H. J. (1973), Two-phase flows in porous media, $A d v$. Hydrosci., 9, 119-202.

Morel-Seytoux, H. J., and J. A. Billica (1985), A two-phase numerical model for prediction of infiltration: Applications to a semi-infinite soil column, Water Resour. Res., 21(4), 607-615, doi:10.1029/ WR021i004p00607.

Mualem, Y. (1976), A new model for predicting the hydraulic conductivity of unsaturated porous media, Water Resour. Res., 12(3), 513-522, doi:10.1029/WR012i003p00513.

Muccino, J. C., W. G. Gray, and L. A. Ferrand (1998), Toward an improved understanding of multiphase flow in porous media, Rev. Geophys., 36(3), 401-422, doi:10.1029/98RG00878.

Niessner, J., and S. M. Hassanizadeh (2008), A model for two-phase flow in porous media including fluid-fluid interfacial area, Water Resour. Res., 44, W08439, doi:10.1029/2007WR006721.

Parker, J. C. (1989), Multiphase flow and transport in porous media, Rev. Geophys., 27(3), 311-328, doi:10.1029/RG027i003p00311.

Parker, J. C., R. J. Lenhard, and T. Kuppusamy (1987), A parametric model for constitutive properties governing multiphase flow in porous media, Water Resour. Res., 23(4), 618-624, doi:10.1029/WR023i004p00618.

Parlange, J.-Y., D. A. Barry, M. B. Parlange, W. L. Hogarth, R. Haverkamp, P. J. Ross, L. Ling, and T. S. Steenhuis (1997), New approximate analytical technique to solve Richards equation for arbitrary surface boundary conditions, Water Resour. Res., 33(4), 903-906, doi:10.1029/ 96WR03846.

Philip, J. R. (1960), General method of exact solution of the concentrationdependent diffusion equation, Aust. J. Phys., 13, 1-12.

Pinder, G. F., and M. A. Celia (2006), Subsurface Hydrology, John Wiley, Hoboken, N. J., doi:10.1002/0470044209.

Pruess, K., C. Oldenburg, and G. Moridis (1999), TOUGH2 user's guide, version 2.0, Rep. $L B N L-43134$, Lawrence Berkeley Natl. Lab, Berkeley, Calif.

Rathfelder, K., and L. M. Abriola (1994), Mass conservative numerical solutions of the head-based Richards equation, Water Resour. Res., 30(9), 2579-2586, doi:10.1029/94WR01302.

Richards, L. A. (1931), Capillary conduction of liquids through porous mediums, Physics, 1, 318-333, doi:10.1063/1.1745010.

Rogers, C., M. P. Stallybrass, and D. L. Clements (1983), On two phase filtration under gravity and with boundary infiltration: Application of a Bäcklund transformation, Nonlinear Anal. Theory Methods Appl., 7(7), 785-799, doi:10.1016/0362-546X(83)90034-2.
Ross, P. J., and J.-Y. Parlange (1994), Comparing exact and numerical solutions of Richards' equation for one-dimensional infiltration and drainage, Soil Sci., 157(6), 341-344, doi:10.1097/00010694199406000-00002.

Sander, G. C., J.-Y. Parlange, V. Kuhnel, W. L. Hogarth, D. Lockington, and J. P. J. O'Kane (1988), Exact nonlinear solution for constant flux infiltration, J. Hydrol., 97(3-4), 341-346, doi:10.1016/0022-1694(88) 90123-0.

Sander, G. C., J. Norbury, and S. W. Weeks (1993), An exact solution to the nonlinear diffusion-convection equation for two-phase flow, $Q . J$. Mech. Appl. Math., 46(4), 709-727, doi:10.1093/qjmam/46.4.709.

Sander, G. C., J.-Y. Parlange, I. G. Lisle, and S. W. Weeks (2005), Exact solutions to radially symmetric two-phase flow for an arbitrary diffusivity, Adv. Water Resour., 28, 1112-1121, doi:10.1016/j.advwatres.2004. 10.011 .

Szymkiewicz, A. (2009), Approximation of internodal conductivities in numerical simulation of one-dimensional infiltration, drainage, and capillary rise in unsaturated soils, Water Resour. Res., 45, W10403, doi:10.1029/2008WR007654.

Tan, K. H. (2005), Soil Sampling, Preparation, and Analysis, 2nd ed., Taylor and Francis, Philadelphia, Pa.

Touma, J., and M. Vauclin (1986), Experimental and numerical analysis of two-phase infiltration in a partially saturated soil, Transp. Porous Media, 1, 27-55, doi:10.1007/BF01036524.

Touma, J., G. Vachaud, and J.-Y. Parlange (1984), Air and water flow in a sealed, ponded vertical soil column: Experiment and model, Soil Sci., 137(3), 181-187, doi:10.1097/00010694-198403000-00008.

Triadis, D., and P. Broadbridge (2010), Analytical model of infiltration under constant-concentration boundary conditions, Water Resour. Res., 46, W03526, doi:10.1029/2009WR008181.

Vachaud, G., M. Vauclin, D. Khanji, and M. Wakil (1973), Effects of air pressure on water flow in an unsaturated stratified vertical column of sand, Water Resour. Res., 9(1), 160-173, doi:10.1029/WR009i001p00160.

van Genuchten, M. T. (1980), A closed-form equation for predicting the hydraulic conductivity of unsaturated soils, Soil Sci. Soc. Am. J., 44, 892-898, doi:10.2136/sssaj1980.03615995004400050002x.

Vauclin, M. (1989), Flow of water and air in soils: Theoretical and experimental aspects, in Unsaturated Flow in Hydrologic Modeling, Theory and Practice, edited by H. J. Morel-Seytoux, pp. 53-91, Kluwer Acad., Dordrecht, Netherlands.

Wang, Z., J. Feyen, D. R. Nielsen, and M. T. van Genuchten (1997), Twophase flow infiltration equations accounting for air entrapment effects, Water Resour. Res., 33(12), 2759-2767, doi:10.1029/97WR01708.

Watson, K. K. (1967), Experimental and numerical study of column drainage, J. Hydraul. Div. Am. Soc. Civ. Eng., 93(HY2), 1-15.

Weeks, E. P. (2002), The Lisse effect revisited, Ground Water, 40, 652-656, doi:10.1111/j.1745-6584.2002.tb02552.x.

Weir, G. J., and W. M. Kissling (1992), The influence of airflow on the vertical infiltration of water into soil, Water Resour. Res., 28(10), 2765-2772, doi:10.1029/92WR00803.

$\mathrm{Xu}, \mathrm{S}$. (2006), Numerical Methods and Computer Implementation (in Chinese), Tsinghua Univ. Press, Beijing.

Youngs, E. G. (1960), The drainage of liquids from porous materials, J. Geophys. Res., 65(12), 4025-4030, doi:10.1029/JZ065i012p04025.

J. J. Jiao and X. Kuang, Department of Earth Sciences, University of Hong Kong, Room 302, James Lee Science Building, Pokfulam Road, Hong Kong, China. (jjiao@hku.hk)

D. Mao, Department of Hydrology and Water Resources, University of Arizona, Tucson, AZ 85721, USA.

L. Wan and X. Wang, School of Water Resources and Environment, China University of Geosciences, Beijing 100083, China. 